\title{
Александрина Ваньке
}

\section{Wendy Bottero. A Sense of Inequality. London: Rowman \& Littlefield Interna- tional, 2020. 262 pp. ISBN 978-1-78348-787-5.}

\begin{abstract}
Александрина Ваньке, Школа социальных наук, Манчестерский университет; Институт социологии Федерального научно-исследовательского социологического центра РАН. Адрес для переписки: School of Social Sciences, Arthur Lewis Building, University of Manchester, Oxford Road, Manchester, M13 9PL, United Kingdom.alexanderina.vanke@manchester.ac.uk.
\end{abstract}

Книга Венди Боттеро «Чувство неравенства» содержит радикальную критику существующих на сегодняшний день подходов к изучению социальных неравенств. Основная критика направлена на постулаты так называемых «толстых» теорий, оперирующих понятиями «натурализация», «символическое господство», «непризнание» («misrecognition»), «гегемония» для объяснения существования социальных неравенств как естественно данных и неосознаваемых простыми людьми. Ключевой аргумент Боттеро состоит в том, что социальные неравенства и отношения субординации могут воспроизводиться и без символического господства (с. 173). В таком случае, почему обычные люди смиряются с неравенствами? Почему неравенства до сих пор существуют? Автор предлагает свой ответ на данный вопрос, исходя из позиций прагматической социологии, феноменологии, интеракционизма, этнометодологии и акторно-сетевой теории. Боттеро утверждает (и это вторая часть ее аргумента), что простые люди не восстают против неравенств не потому, что не осознают их - по ее мнению, наоборот, они как раз хорошо ощущают неравенства, - а в силу наличия повседневных ограничений, таких как неверие в собственные силы что-либо изменить, социальные условности, взятые на себя обязательства, принятые договоренности - одним словом, каждодневная рутина, предполагающая практическую вовлеченность (с. 11, 173).

Автор методично подкрепляет свой аргумент критическим анализом теорий отношений господства и подчинения и детальным разбором широкого круга эмпирических исследований, обращаясь не только к примерам из стран глобального Севера и Запада, но и глобального Юга и Востока (с. 15). Книга состоит из восьми глав, всю работу условно можно разделить на три части. В главах 1-4 раскрывается суть уже ставших классикой подходов к понимаю неравенств и отношений господства/подчинения: это теории Пьера Бурдье (Bourdieu 1984), Антонио Грамши (Gramsci 1971), Мишеля Фуко (Foucault 1979) и других - к их постулатам автор ставит ряд критических вопросов и показывает ограничения этих теорий. Вторая часть (главы 5-6) рассматривает способы реагирования на неравенства: от повседневного сопротивления до открытых коллективных протестов. Это теории Джеймса Скотта (Scott 1990), Асефа Баята (Bayat 2013), Френсис Фокс Пивен (Piven 2008) и др. И, наконец, заключительные главы (7-8): в них автор обозначает свою позицию и подытоживает основные аргументы с отсылкой к теориям Джона Дьюи (Dewey 1938), Джорджа Герберта Мида (Mead 1934), Альфреда Щютца (Schütz 1964), Бруно Латура (Latour 
2005) и др. Задача настоящей рецензии состоит не в том, чтобы подробно рассказать о содержании книги, а в том, чтобы показать, чем она может быть интересна российским читателям. Поэтому далее я обозначу ряд моментов, которые, как мне кажется, могут быть любопытны исследователям, работающим в российском поле.

В главе 1 («0граниченное видение?») Боттеро объясняет, что под «чувством неравенства» она имеет в виду то, как люди воспринимают, понимают и реагируют на субъективные неравенства. В данном случае, прежде всего, речь идет об «изучении "чувства неравенства" людей через отношения и восприятие, рефлексивные и сознательные ценности и верования, выражение чувств несправедливости и унижения достоинства, борьбу против неравенства посредством организованного протеста, сопротивления и обыденного неподчинения, но также и через более неявные, вписанные в тело и аффективные способы, с помощью которых люди “знают" и "чувствуют" мир» (с. 1-2). Это авторское определение расширяет классическое понимание объективных неравенств и открывает возможность для изучения неравных властных отношений на уровне повседневной жизни и практического знания, приобретенного в конкретных ситуациях. Как отмечает Боттеро в главе 2 («0тношение к неравенству»), наше субъективное восприятие неравенства во многом связано с контекстом и частично зависит от того, с кем мы себя сравниваем в жизни (с. 33). А сравниваем мы себя зачастую с людьми из нашего круга: с теми, кто живет с нами в одном доме, дворе или районе, окончил то же самое учебное заведение, работает с нами в одной организации (с. 61).

Понимание «чувства неравенства» как укорененного в конкретных контекстах делает данное понятие привлекательным для российских исследователей. Различия в социальной и медийной политике в разных странах будут накладывать опечаток на то, как мы воспринимаем и ощущаем социальные неравенства на уровне повседневности. Например, в главе 3 «Не признавая неравенство» Боттеро ссылается на исследование Трейси Шилдрик и Роберта МакДоналда (Shildrick and McDonald 2013) о восприятии бедности в Британии, согласно которому жители английских депрессивных городов отрицают то, что они бедные, и сами воспроизводят стереотипы о бедняках как о попрошайках (с. 74). Подобный неолиберальный дискурс транслируется британскими медиа и стигматизирует депривированные группы, изображая их как недостойных людей, незаслуженно получающих социальные пособия. Другую ситуацию мы наблюдаем в России, где жители депрессивных регионов открыто называют себя бедными, и для них нет ничего зазорного в том, чтобы получать социальные пособия. Более того, недавние публичные высказывания в адрес бедных, которые «начнут рожать» детей ради получения материнского капитала, вызвали бурную негативную реакцию в российском обществе и медиа ${ }^{1}$. В этом смысле понимание «чувства неравенства» как произрастающего из конкретных ситуаций делает данное понятие рабочим исследовательским инструментом и за пределами западных обществ, хотя оно и требует некоторой поправки при переносе в другие национальные контексты.

${ }^{1}$ См. подробнее: РИА Новости, «Водонаева объяснила слова о “быдле”, получающим маткапитал», 18 февраля 2020 г. https://ria.ru/20200118/1563569948.html. 
Второй момент, на который мне хотелось бы обратить внимание, - детальная критика структуралистских подходов к объяснению жизнестойкости неравенств. В данном случае я говорю как исследовательница, стоящая на позициях генетического структурализма. Из обоснованной критики, разворачивающейся на страницах книги, можно получить четкое представление об основных постулатах этих подходов. Развивая аргумент Скотта о «толстых» и «тонких» теориях (Scott 1990:72-74), Боттеро утверждает, что Бурдье, Грамши и Фуко переоценивают силу «символического господства», «гегемонии» и «дисциплинарной власти» в отношении воспроизводства неравенств. Вслед за Люком Болтански Боттеро полагает ${ }^{2}$, что обычные люди не такие наивные, как привыкли думать социальные ученые: люди обладают практическим знанием и чувством субординации, которые приобретаются через повседневные взаимодействия. Больше всего критики достается Бурдье за ограниченность его понятий «натурализации» (принятия социального порядка как естественно данного) и «непризнания» (неосознания) неравенств. В отличие от Бурдье, Боттеро утверждает, что люди могут делать вид, что смиряются с неравенствами и субординацией, но в то же время использовать приемы неповиновения и уклонения от них на уровне микродействий. Данный аргумент согласуется с тем, что Скотт называет «публичными» и «скрытыми транскриптами» (Scott 1990:2, 4).

Боттеро продолжает наступление на генетический структурализм и в главе 4 «Аффективные неравенства», где критикует понятие «габитус» (набор социальных диспозиций, предопределяющих действия людей), для которого, как она пишет, акты сопротивления и протеста, согласно Бурдье, аномальны (с. 93). Боттеро задается вопросом: если габитус не склонен к протесту и сопротивлению неравенствам, тогда почему же по всему миру то тут, то там возникает возмущение и зарождаются социальные движения? И правда: недавние массовые протесты в Чили, Гонконге и других странах могут говорить о том, что люди не готовы мириться с социальными неравенствами. Данная ситуация позволяет задуматься об аффективном измерении социальной борьбы и сместиться с аргумента о символическом доминировании, воспроизводящем неравенства, на «критические способности людей, этические диспозиции и моральные обоснования», объясняющие их участие или неучастие в борьбе с неравенствами (с. 92). С этим аргументом Боттеро трудно не согласиться, однако можно задать по поводу него ряд вопросов. Если люди протестуют против неравенств, значит ли это, что символического господства не существует вовсе? И значит ли это, что габитус, с которым мы имеем дело в конкретной ситуации эмпирического исследования, так же не способен на протест или сопротивление?

Третья причина, по которой книга, на мой взгляд, достойна внимания российского читателя, заключается в том, каким образом Боттеро предлагает изучать способы реакций простых людей на повседневные неравенства. В главах 5 («Протестуя против неравенств») и 6 («Сопротивляясь неравенствам») она рассматривает теории социальных движений и быстрыми темпами развивающуюся область

2 Wendy Bottero, "A Sense of Inequality," interview by Dave 0'Brien, New Books Network Podcast, January 20, 2020. https://newbooksnetwork.com/wendy-bottero-a-sense-of-inequality-roman-and-littlefield-2020/. 
исследований сопротивления. Наиболее интересным мне видится то, что в этих главах речь идет о коллективных действиях, принимающих неконвенциональные формы, отличные от представлений западных теоретиков о том, какими движения должны быть. Ссылаясь на исследование Асефа Баята о низовых кооперациях и неформальных связях уличных торговцев в Азии (Bayat 2013), Боттеро пишет о социальных не-движениях, которые, несмотря на свою внешнюю «неорганизованность», тем не менее участвуют в изменении городских ландшафтов и властных отношений. Однако, как я считаю, для российского общества еще более актуальными могут быть подходы, рассматривающие реакции на неравенства через практики повседневного сопротивления, понимаемые как инфраполитики (infrapolitics) в терминологии Скотта. И несмотря на то, что данные подходы тоже имеют свои ограничения и подвергаются сильной критике в силу неочевидности границы между повседневным сопротивлением и практиками приспособления, я вижу в них пространство для теоретизации и эмпирических исследований в российском контексте.

И, наконец, книга может вызывать интерес у приверженцев прагматических подходов, поскольку в заключительных главах 7 («Придавая смысл неравенству») и 8 («Заключение: анализируя неравенства») Боттеро делает своего рода теоретический рефрейминг, помещая повседневные неравенства и способы обращения с ними в проблемное поле прагматической социологии, социальной феноменологии и акторно-сетевой теории. Такой шаг может вызвать любопытство у российского читателя, поскольку в отечественной социологии исследования повседневных неравенств сквозь призму данных подходов - нечастое явление. Не раскрывая всех деталей «Чувства неравенства», я, пожалуй, завершу на этом рецензию и позволю читателям самим прочитать книгу и разобраться, согласны ли они с аргументами автора или готовы задать ряд вопросов.

\section{СПИСОК ЛИТЕРАТУРЫ}

Bayat, Asef. 2013. Life as Politics: How Ordinary People Change the Middle East. Stanford, CA: Stanford University Press.

Bourdieu, Pierre. 1984. Distinction: A Social Critique of the Judgement of Taste. London: Routledge and Kegan Paul.

Dewey, John. 1938. Logic: The Theory of Inquiry. New York: Henry Holt.

Foucault, Michel. 1979. Discipline and Punish: The Birth of the Prison. Harmondsworth, UK: Penguin.

Gramsci, Antonio. 1971. Selections from the Prison Notebooks of Antonio Gramsci, ed. and trans. by Quintin Hoare and Geoffrey Nowell Smith. New York: International Publishers.

Latour, Bruno. 2005. Reassembling the Social: An Introduction to Actor-Network-Theory. 0xford: 0xford University Press.

Mead, George Herbert. 1934. Mind, Self \& Society, ed. by Charles W. Morris. Chicago: University of Chicago Press.

Piven, Francis Fox. 2008. "Can Power from Below Change the World?" American Sociological Review 73(1):1-14.

Schütz, Alfred. 1964. Collected Papers. Vol. 2, Studies in Social Theory. The Hague: Martinus Nijhoff.

Scott, James C. 1990. Domination and the Arts of Resistance: Hidden Transcripts. New Haven, CT: Yale University Press.

Shildrick, Tracy, and Robert McDonald. 2013. “Poverty Talk: How People Experiencing Poverty Deny Their Poverty and Why They Blame 'The Poor.'" Sociological Review 61(2):285-303. 